\title{
Increased expression of insulin-like growth factor I in skin in amyotrophic lateral sclerosis
} Seiitsu Ono, Jianguo Hu, Takashi Imai, Natsue Shimizu, Mayumi Tsumura,
Hachiro Nakagawa

\begin{abstract}
Objectives-Insulin-like growth factor I (IGF-I) has potent effects on motor neuron survival and is being studied as a possible therapeutic agent for ALS. However, little is known concerning IGF-I in the skin of patients with amyotrophic lateral sclerosis (ALS). The aim was to evaluate IGF-I immunoreactivity of skin in patients with ALS.

Methods- IGF-I immunoreactivity of skin from 18 patients with ALS and 16 controls was examined.

Results-IGF-I immunoreactivity was markedly positive in the epidermis and dermal blood vessels and glands and was moderately positive in the reticular dermis in all patients with ALS. On the other hand, the epidermis and dermal blood vessels and glands and the reticular dermis showed a weak IGF-I immunoreactivity in controls. The optical density for IGF-I immunoreactivity of the epidermis and dermal blood vessels and glands, and the reticular dermis in patients with ALS was significantly higher than in diseased controls, and was significantly increased with duration of illness.

Conclusions-These data suggest that a metabolic alteration of IGF-I may take place in the skin of patients with ALS. (F Neurol Neurosurg Psychiatry 2000;69:199-203)
\end{abstract}

Department of Neurology, Teikyo University School of Medicine, Ichihara Hospital, Ichihara, Japan

$\mathrm{S}$ Ono

N Shimizu

Research and Development Center, BML, 1361 Matoba, Kawagoe, Japan $\mathrm{J} \mathrm{Hu}$

M Tsumura

H Nakagawa

Department of Neurology, National Sanatorium Chiba Higashi Hospital, Chiba, Japan

T Imai

Correspondence to: $\mathrm{Dr} \mathrm{J} \mathrm{Hu}$

hu@alk.co.jp

Received 14 September 1999 and in final form

7 April 2000

Accepted 12 April 2000
Keywords: amyotrophic lateral sclerosis; insulin-like growth factor I; immunohistochemistry

Sporadic amyotrophic lateral sclerosis (ALS) is an idiopathic and progressive neurodegenerative disorder of unknown aetiology primarily characterised by loss of motor neurons in the cerebral cortex and spinal cord. ${ }^{1}$ There are many hypotheses about the cause of this disease. One general theory of the underlying cause of ALS is that motor neurons lack crucially needed trophic factors, resulting in neuronal degeneration, cell death, and atrophy of target muscles. ${ }^{2}$

Insulin-like growth factor I (IGF-I) is a naturally occurring single chain polypeptide consisting of 70 amino acids. It is expressed by various tissues including skeletal muscle and the CNS. Receptors for IGF-I are found throughout the body, including spinal motor neurons, muscle, and brain. ${ }^{3}$ There has been recent evidence supporting the hypothesis of neurotrophic effects of IGF-I. It induces brain growth and myelination in transgenic mice, ${ }^{4}$ stimulates the regeneration of lesioned peripheral nerves, ${ }^{5}$ promotes survival of motor neurons in vitro, ${ }^{6}$ induces marked collateral sprouting of intramuscular nerve fibres, ${ }^{7}$ and increases myelination with inhibition of demyelination in cultured organotypic nerve tissues. ${ }^{8}$ It has been also shown to reduce spinal cord motor neuron death in vitro, to lower programmed death of motor neurons during the development of the embryonic chicken, and to increase motor neuronal sprouting in degenerated muscles. ${ }^{9}$ For these reasons, IGF-I may be involved, directly or indirectly, in the aetiology of various neurodegenerative disorders and, therefore, might be of therapeutic value for these diseases.

In $1981 \mathrm{Appel}^{10}$ put forward the hypothesis that the reduced availability of neurotrophic factors might lead to degeneration of motor neurons in motor neuron diseases. Since then it has become apparent that several neurotrophic agents, such as IGF-I, may act during development and also during conditions of cell degeneration to support the survival of motor neurons. ${ }^{11}$ IGF-I increases muscle strength and fibre size in the wobbler mouse model of motor neuron diease. ${ }^{12}$ These findings may have important implications for the potential of IGF-I as a therapeutic agent for the treatment of ALS. Although the role of neurotrophic factors in the pathogenesis of human motor neuron diseases remains unclear, the availability of IGF-I as a recombinant protein has allowed its study as an experimental therapy for motor neuron disease, including $\mathrm{ALS}^{2{ }^{3}}$ Recently, two randomised double blind, placebo controlled clinical trials that used recombinant human IGF-I (rhIGF-I) were conducted in patients with mild to moderate ALS. ${ }^{13}{ }^{14}$ Compared with the placebo, $0.1 \mathrm{mg} / \mathrm{kg} /$ day $\mathrm{rhIGF}-\mathrm{I}$ significantly attenuated the progression of ALS. ${ }^{13}$ These studies merit emphasis that IGF-I is biologically and structurally distinct from ciliary neurotrophic factor and brain derived neurotrophic factor. ${ }^{13}$

However little is known about IGF-I in the skin of patients with ALS. Because IGF-I is being studied as a possible therapeutic agent for ALS, a disorder in which numerous alterations are seen in the skin as well as in the nervous system, we have examined IGF-I immunoreactivity in the skin of patients with ALS.

\section{Patients and methods}

\section{PATIENTS}

Our subjects were 18 patients with ALS (mean age (SD) 61.3 (7.4) years; range, 45-68 years; 12 men and six women) and 16 controls with other neurological or muscular diseases (mean age (SD) 57.2 (9.6) years; range, 48-72 years; 11 men and five women). The diagnosis of 

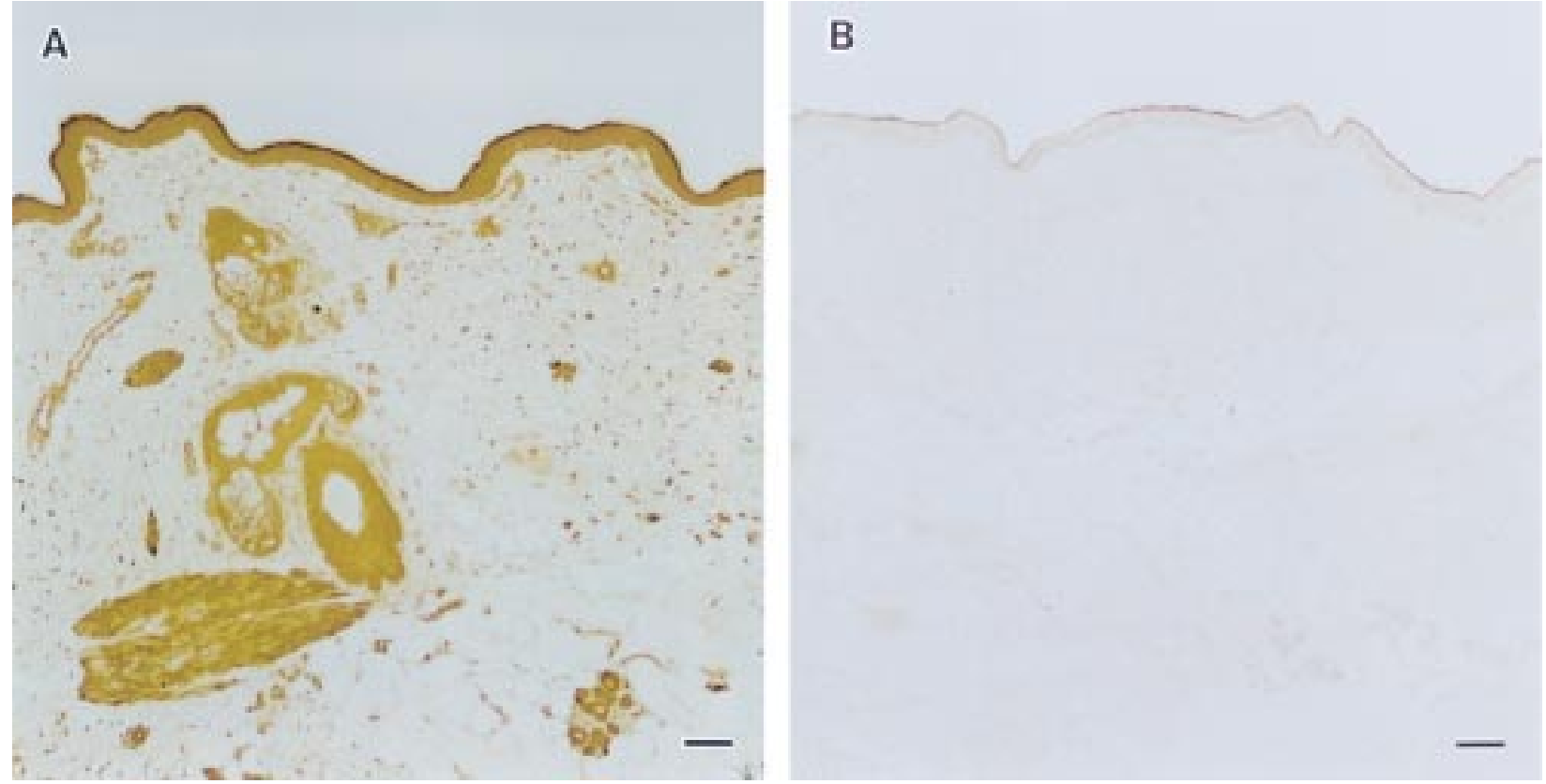

Figure 1 Immunohistochemical staining for IGF-I in skin. (A) The epidermis and dermal blood vessels and glands were markedly positive and the reticular dermis was moderately positive in a patient with ALS compared with (B) those of a control patient. Bars=100 $\mu m$.

ALS was based on a detailed history and physical examination, extensive haematological, biochemical, electrophysiological, and radiological testing, and muscle biopsy. The patients with ALS all had progressive weakness and muscular atrophy associated with signs of both upper and lower motor neuron dysfunction with no sensory abnormalities, clear evidence of progression, normal nerve conduction velocities and late responses, and electrophysiological evidence of diffuse denervation. The diagnosis of ALS was made according to the El Escorial criteria of the World Federation of Neurology and all patients with ALS had clinically definite ALS. ${ }^{15}$ Twelve patients with ALS had bulbar symptoms, which were deemed to be severe in five. The diagnoses in control subjects were chronic inflammatory demyelinating polyradiculoneuropathy (two), polymyositis (two), Alzheimer's disease (one), periarteritis nodosa (one), Parkinson's disease (two), spinocerebellar degeneration (two), neuralgic amyotrophy (two), multiple sclerosis (one), myasthenia gravis (one), mitochondrial encephalomyopathy (one), and progressive supranuclear palsy (one). The age and sex distribution of the two groups were comparable. Five patients with ALS with moderate to severe bulbar symptoms and five control patients (Alzheimer's disease, Parkinson's disease, spinocerebellar degeneration, mitochondrial encephalomyopathy, and progressive supranuclear palsy in one patient each) incapable of self feeding because of dysphagia or the difficulty in taking food and water used tube feeding or a feeding gastrostomy. There were no differences in diet between these patients with ALS and the controls. The duration of the tube feeding was 0.8 (SD 0.2) years in patients with ALS and 0.7 (SD 0.3) years in control patients. Both patients with ALS and controls who required tube feeding or a feeding gastrostomy received between 1500 and 1800 calories/day, and had a good nutritional status. Height $(\mathrm{m})$ and weight $(\mathrm{kg})$ were recorded and $\left(\mathrm{wt} / \mathrm{m}^{2}\right)$ was calculated. There was no significant difference in the body mass index between patients with ALS (19.5 (SD 4.5)) and control subjects (20.7 (SD 4.8)). Informed consent was obtained from all patients with ALS and all the control patients.

Functional ability in patients with ALS and controls was measured using the Barthel disability scale. ${ }^{16}$ The total average score was 9.3 (range, 4.0-14.0) in patients with ALS and 10.4 (range, 3.0-15.0) in control patients. The average score for feeding was 0.86 in patients with ALS and 1.13 in controls. The two groups were similar in both the total average score and the average score for feeding in the Barthel index.

TISSUE PROCESSING

Two $3 \mathrm{~mm}$ biopsy specimens of skin overlying the left biceps from all patients with ALS and all controls were obtained after local anaesthesia with $1 \%$ procaine. Biopsy sites were free of atrophic or hypertrophic scars, recent bruises, or induration. Special care was taken to minimise stress on the tissue when performing the biopsy. Each specimen was fixed in $4 \%$ formaldehyde solution. Observations were made in all cases by three examiners who had no information on the clinical history and condition of the patient providing the skin specimen. All samples were fixed for 48 hours in $10 \%$ formalin containing $1 \%$ cetylpyridinium chloride, then embedded in paraffin.

\section{IMMUNOHISTOCHEMISTRY}

Sections $6 \mu \mathrm{m}$ thick from each paraffin block were deparaffinised with xylene and hydrated in ethanol and phosphate buffered saline (PBS, $\mathrm{pH} 7.4$ ), and then treated with $0.3 \%$ hydrogen peroxide in anhydrous methanol for $60 \mathrm{~min}$ utes. After treatment with trypsin, the sections 

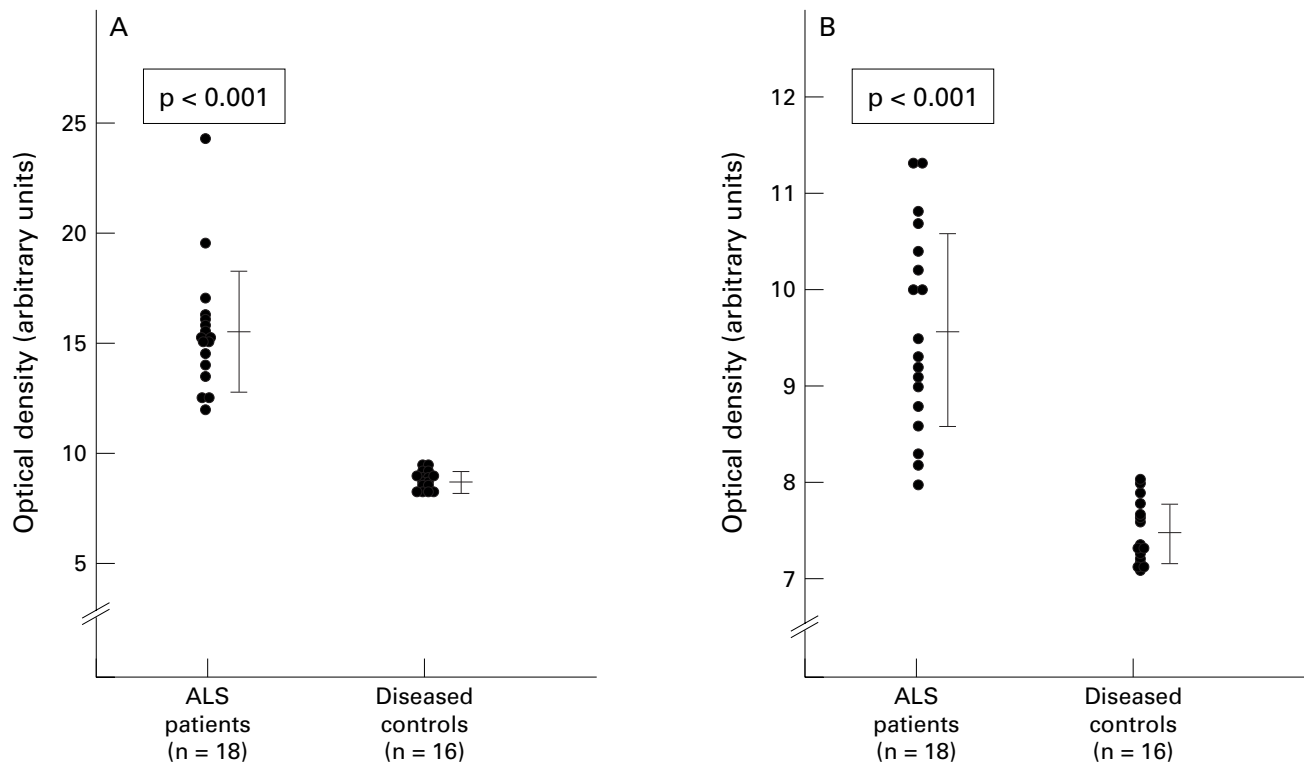

Figure 2 Optical density measurements of IGF-I immunoreactivity in the skin in patients with ALS and in controls. (A) The density for IGF-I immunoreactivity in the epidermis and dermal blood vessels and glands was significantly higher $(p<0.001)$ in patients with ALS than in controls. Bars show mean (SD). (B) The density for IGF-I immunoreactivity in the reticular dermis was significantly higher $(p<0.001)$ in patients with ALS than in controls. Bars show mean (SD).

were incubated with rabbit serum for 20 minutes to block the non-specific binding of antibodies. The sections were reacted with primary antibodies and stained for immunoreactivity by the avidin-biotin peroxidase complex (ABC) method, using ABC kits (Vector Laboratories, Burlingame, CA, USA). ${ }^{17}$ Monoclonal antibody against IGF-I was purchased from $\mathrm{R}$ and D systems (Minneapolis, MN, USA) and diluted 1:75 with PBS ( $\mathrm{pH} 7.2$ ). Consecutive sections were also stained with mouse serum in place of primary antibody to verify the specificity of the staining. After slight counterstaining with haematoxylin, samples were mounted and IGF-I immunoreactivity was assessed in relation to corresponding control haematoxylin and eosin stained serial sections.

RELATIVE OPTICAL DENSITY MEASUREMENT From each patient, about 50 randomly selected sections obtained from the paraffin blocks were studied. The images of the sections were scanned by Scan Jet 4c (Hewlett Packard, Tokyo, Japan) and Adobe Photoshop software

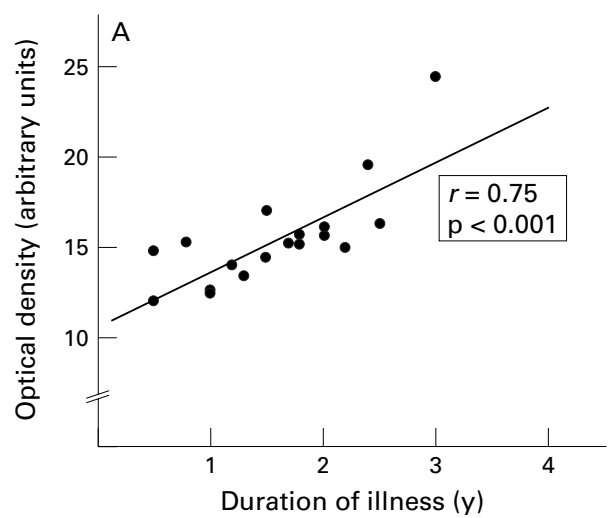

version $4.0 \mathrm{~J}$. A densitometric analysis was performed using KS100 image software version 2.0. Total IGF-I content was obtained by delimiting the positive areas for immunolabelling on each section, determining their range of grey levels, and marking the areas to be analysed. After that, they were measured and evaluated by an image analysis program. The integrated optical density (IOD) was the parameter tested and the amount of IGF-I for each patient was represented by the total of the different measurements taken. All the sections were analysed by the same examiner who had no information on the clinical history and condition of the patient providing the skin specimen.

\section{STATISTICAL ANALYSIS}

Statistical comparisons were made by two tailed Student's $t$ test with $\mathrm{p}<0.05$ as the significance level. Correlation coefficients were calculated by the least squares method. Results are expressed as the mean (SD).

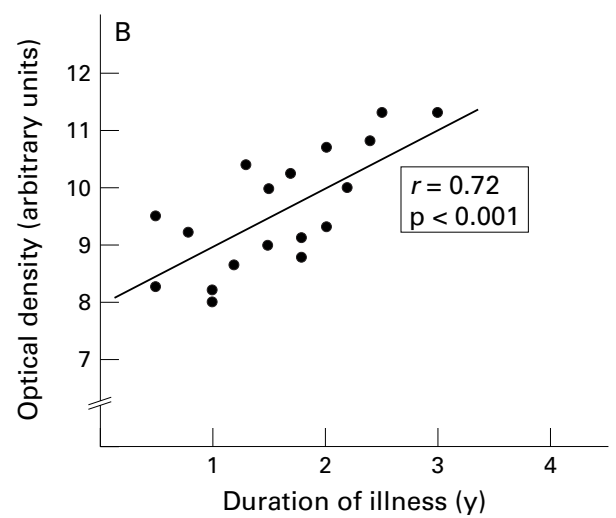

Figure 3 Correlation of duration of illness with the optical density for IGF-I immunoreactivity in patients with ALS. (A) There was a significant positive relation $(r=0.75, p<0.001)$ between the density of immunoreactivity in the epidermis and dermal blood vessels and glands and duration of illness. (B) There was a significant positive relation $(r=0.72, p<0.001)$ between the density of immunoreactivity in the reticular dermis and duration of illness. 


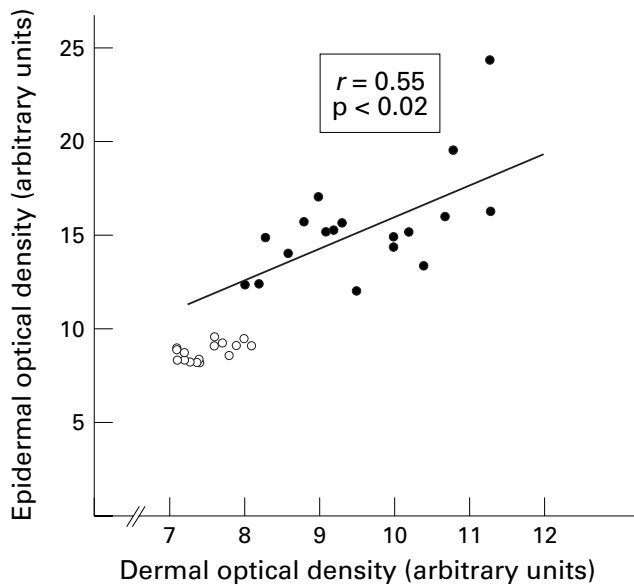

Figure 4 Correlation of the optical density for IGF-I immunoreactivity in the epidermis and dermal blood vessels and glands to that in the reticular dermis in patients with ALS (closed circles) and in controls (open circles). There was a significant positive relation $(r=0.55, p<0.02)$ in patients with ALS

\section{Results}

Insulin-like growth factor I immunoreactivity was markedly positive in the epidermis and dermal blood vessels and glands and was moderately positive in the reticular dermis in all patients with ALS (fig $1 \mathrm{~A}$ ). On the other hand, the epidermis, dermal blood vessels and glands, and the reticular dermis showed a weak IGF-I immunoreactivity in controls even after repeated antigen retrieval trials (fig $1 \mathrm{~B}$ ).

The optical density for IGF-I immunoreactivity of the epidermis and dermal blood vessels and glands in patients with ALS (mean (SD) $15.5(2.8))$ was significantly higher $(\mathrm{p}<0.001)$ than in controls $(8.8(0.5)$, fig $2 \mathrm{~A})$. The optical density of the reticular dermis in patients with ALS (mean (SD) 9.6 (1.0)) was also significantly higher $(\mathrm{p}<0.001)$ than in controls (7.5 (0.3), fig $2 \mathrm{~B})$. The densities of IGF-I immunoreactivity in patients with ALS showed a progressive increase in relation to duration of illness. This positive correlation was highly significant $(r=0.75, \quad \mathrm{p}<0.001$ and $r=0.72$, $\mathrm{p}<0.001$, respectively) in the epidermis, dermal blood vessels and glands, and in the reticular dermis (fig 3). The density for IGF-I immunoreactivity of the epidermis and dermal blood vessels and glands was positively and significantly $(r=0.55, \mathrm{p}<0.02)$ related to that of the reticular dermis in patients with ALS, but not in controls (fig 4). There was no relation between the IGF-I optical density and the total average score and the average score for feeding in the Barthel index in patients with ALS or in controls.

\section{Discussion}

The most significant finding in the skin of patients with ALS in our study was the increased IGF-I immunoreactivity, which was even more significant in patients with ALS with a longer duration of disease. In addition, weakly stained diseased controls remained unchanged even after the immunohistochemical procedure was modified to optimally retrieve lost antigens. Thirteen patients with ALS and seven controls had marked muscular atrophy beneath the biopsied skin, and seven patients with ALS and five controls were bedridden over a period of 1 year. Thus the skin abnormalities in patients with ALS were not secondary changes as a consequence of weight loss, muscular atrophy, loss of active movement in the biopsied limb, or bedridden state, indicating that the increased IGF-I immunoreactivity of skin does not reflect nutritional status or activity dependent skin remodelling. Thus the increase in IGF-I immunoreactivity of skin in ALS might indicate an augmentation of IGF-I content due to reduced degradation, increased synthesis, or increased binding of circulating IGF-I by skin components.

The role of IGF-I in human skin is still not completely understood. Insulin-like growth factor I stimulates the synthesis and deposition of various extracellular matrix proteins important in wound healing ${ }^{18}$ and may play a significant part in both the early and late wound environments. ${ }^{19}$ It is expressed locally in response to tissue injury and presumed to be an essential part of the wound healing machinery. ${ }^{20}{ }^{21}$ Further, IGF-I has been shown to enhance healing when added exogeneously to healing wounds. ${ }^{20}$ Therefore, it may be advantageous to augment growth factor concentrations to achieve accelerated normal healing or to correct impaired healing. These findings imply that the increased IGF-I immunoreactivity of skin in ALS may be related to the absence of bedsore formation even in the terminal stages of ALS. ${ }^{22}$

Insulin-like growth factor I selectively stimulates gene expression of type III collagen in the granulation tissue but not type I collagen. ${ }^{23}$ Spanheimer et $a l^{24}$ have presented data showing a strong relation between IGF-I concentrations and changes in collagen biosynthesis in rats in response to short term caloric restriction. Studies of lifetime caloric restriction in rodents have shown that such a regimen results in significant changes in collagen cross linking. ${ }^{23-25}$ Several morphological and biochemical studies of skin in patients with ALS have demonstrated (1) a significant negative correlation between the diameter of collagen fibrils and duration of illness ${ }^{26} ;(2)$ decreased content of collagen ${ }^{27} ;(3)$ alteration of cross linking of collagen ${ }^{28}$; and (4) increased solubility of collagen. ${ }^{29}$ Thus these findings unique to $\mathrm{ALS}^{26-29}$ may be associated with the increased IGF-I immunoreactivity of skin in ALS shown in the present study.

We thank Dr David L McIlwain, Professor of the Department of Cell and Molecular Physiology of the University of North Carolina at Chapel Hill, for his valuable comments and encouragement, and Mrs Sanae Fujii, Mr Akira Aso, and Mr Kenichi Hasegawa for their technical assistance.

1 Hirano A, Iwata M. Pathology of motor neurons with special reference to amyotrophic lateral sclerosis and related diseases. In: Tsubaki T, Toyokura Y, eds. Amyotrophic lateral sclerosis. Baltimore: University Park Press, 1979;107-33.

2 Doré S, Kar S, Quirion R. Rediscovering an old friend, IGF-I: potential use in the treatment of neurodegenerative diseases. Trends Neurosci 1997;20:326-31.

Reconbinant human Lange DJ, Felice KJ, Festoff BW, et al. Reconbinant huma insulin-like growth factor-I in ALS: description of a double-blind, placebo-controlled study. North America ALS/IGF-I Study Group. Neurology 1996;47(suppl 2): 
4 Carson MJ, Behringer RR, Brinster RL, et al. Insulin-like growth factor I increases brain growth and central nervous system myelination in transgenic mice. Neuron 1993;10:

Sjoberg J, Kanje M. Insulin-like growth factor (IGF-I) as a stimulator of regeneration in the freeze-injured rat sciatic nerve. Brain Res 1989;485:102-8.

6 Ang LC, Bhaumick B, Munoz DG, et al. Effects of astrocytes, insulin, and insulin-like growth factor I on the survival of motoneurons in vitro. $\mathcal{F}$ Neurol Sci 1992;109: 168-72. 7 Caroni P, Grandes P. Nerve sprouting in innervated adult insulin-like growth factors. F Cell Biol 1990;110:1307-17.

8 Roth GA, Spada V, Hamill K, et al. Insulin-like growth factor I increases myelination and inhibits demyelination in cultured organotypic nerve tissue. Brain Res Dev Brain Res 1995;88:102-8

9 Lewis M, Vaught J, Neff TN, et al. The potential of insulin like growth factor-I as a therapeutic for the treatment of neuromuscular disorders. Ann NY Acad Sci 1993;692:2018 .

10 Appel SH. An unifying hypothesis for the cause of amyotrophic lateral sclerosis, parkinsonism and Alzheime disease. Ann Neurol 1981;10:499-505.

11 Martin JE. Neurotrophic factors and neurodegeneration. In: Leigh PN, Swash M, eds. Motor neuron disease. New York: Springer Verlag, 1995:241-58.

12 Hanta D, Akaaboune M, Lagord C, et al. Beneficial effects of insulin-like growth factor-I on wobbler mouse motoneuron disease. F Neurol Sci 1995;129(suppl):122-6.

13 Lai EC, Felice KJ, Festoff BW, et al. Effect of recombinant human insulin-like growth factor-I on progression of ALS. A placebo-controlled study. Neurology 1997;49:1621-30.

14 Borasio GD, Robberecht W, Leigh PN, et al. A placebocontrolled trial of insulin-like growth factor-I in amyotrophic lateral sclerosis. Neurology 1998;51:583-6.

15 Brooks BR. El Escorial World Federation of Neurology criteria for the diagnosis of amyotrophic lateral sclerosis. $f$ Neurol Sci 1994:124(suppl):96-107.

16 Mahoney FI, Barthel DW. Functional evaluation: the Barthel index. Maryland State Medical fournal 1965;14: $61-5$.
17 Hsu SM, Raine L, Fanger H. Use of avidin-biotinperoxidase complex (ABC) in immunoperoxidase techniques: a comparison between $\mathrm{ABC}$ and unlabeled antibody (PAP) procedures. F Histochem Cytochem 1981;29: $577-80$.

18 Goldstein RH, Poliks CF, Pilch PF, et al. Stimulation of collagen formation by insulin and insulin-like growth factor I in culture of human lung fibroblasts. Endocrinology 1989;124:964-70.

19 Bhora FY, Dunkin BJ, Batzri S, et al. Effect of growth factors on cell proliferation and epithelialization in human skin. $\mathcal{F}$ Surg Res 1995;59:236-44.

20 Gartner MH, Benson JD, Caldwell MD. Insulin-like growth factors I and II expression in the healing wound. F Surg Res 1992;52:389-94.

21 Bennett NT, Schultz GS. Growth factors and wound healing: biochemical properties of growth factors and their receptors. Am ₹ Surg 1993;165:728-37.

22 Furukawa T, Toyokura Y. Amyotrophic lateral sclerosis and bedsores. Lancet 1976;i:862.

23 Reiser K. Effect of aging and diet restriction on collagen synthesis and crosslinking in a model of wound healing. fournal of Geriatric Dermatology 1993;1:87-96.

24 Spanheimer R, Zlatev T, Umpierrez G, et al. Collagen production in fasted and food-restricted rats: response to duration and severity of food deprivation. $\mathcal{F}$ Nutr 1991;121: $518-24$

25 Reiser KM. Influence of age and long-term dietary restriction on enzymatically mediated crosslinks and nonenzymatic glycation of collagen in mice. $f$ Gerontol 1994;49:71B-9.

26 Ono S, Toyokura Y, Mannen T, et al. Amyotrophic lateral sclerosis: histological, histochemical, and ultrastructural abnormalities of skin. Neurology 1986;36:948-56.

27 Ono S, Mechanic GL, Yamauchi M. Amyotrophic lateral sclrosis: unusually low content of collagen. $\mathcal{F}$ Neurol Sci 1990;100:234-7.

28 Ono S, Yamauchi M. Collagen cross-linking of skin in patients with amyotrophic lateral sclerosis. Ann Neurol 1992;31:305-10

29 Ono S, Yamauchi M. Amyotrophic lateral sclerosis: increased solubility of skin collagen. Neurology 1992;42: $1535-9$. 